\title{
Uma experiência do uso de narrativas na formação de estudantes de Medicina
}

Lenita Barreto Lorena Claro(a)

Anna Alice Amorim Mendes(b)

\section{Introdução}

O envelhecimento populacional e o aumento da prevalência das doenças crônico-degenerativas trouxeram desafios para a prática médica, que precisou reavaliar suas metas curativas para ceder lugar ao objetivo de cuidar, a longo prazo, de pessoas portadoras de problemas de saúde. Os cursos de Medicina têm sido reformulados, com o objetivo de incorporar novas competências à formação médica, utilizando abordagens como a narrativa. Os seres humanos, ao adquirirem a capacidade de comunicação por meio da linguagem, logo tornaram-se contadores de histórias. As histórias mantêm vivas as memórias, atribuem significado às ocorrências da vida e permitem que fatos indesejáveis e caóticos possam ser organizados e adquirir coerência e sentido ${ }^{1,2}$.

A prática médica requer competências narrativas, que envolvem a habilidade de ouvir a narrativa da pessoa enferma, apreender e interpretar seus significados e ser movido a cuidar dessa pessoa ${ }^{1,3,4}$. Essas competências tornam o médico mais apto a praticar a medicina de uma forma reflexiva e empática 5 . Sua aquisição envolve um tipo de aprendizado transformativo, que transcende o nível cognitivo, para atuar também nos níveis afetivo e experiencial, ampliando a percepção e a compreensão do estudante ${ }^{6}$.

A medicina narrativa é uma abordagem que vem sendo construída desde o início do século atual, com a colaboração de diversos autores e que se fundamenta em ouvir os pacientes com atenção e empatia e utilizar suas histórias como ferramentas para seu cuidado 7,8 . Considera a saúde e a doença como processos que são essencialmente experienciais em sua natureza, e, por isso, é indispensável ouvir o que é expresso e narrado por aquele que vivencia esses processos ${ }^{9}$. Essa compreensão facilita que uma abordagem holística e mais adequada às necessidades do paciente seja utilizada nas decisões diagnósticas e terapêuticas ${ }^{10}$.

Diversas escolas médicas em todo o mundo têm incorporado, em anos recentes, o exercício das narrativas, tendo em vista formar profissionais mais aptos para valorizar a perspectiva dos pacientes na compreensão do processo de adoecimento e nas formas de atenção e cuidado dispensadas $3,6,8,11-16$.

O objetivo deste trabalho é descrever uma experiência de utilização da abordagem narrativa no curso de Medicina da Universidade Federal Fluminense.

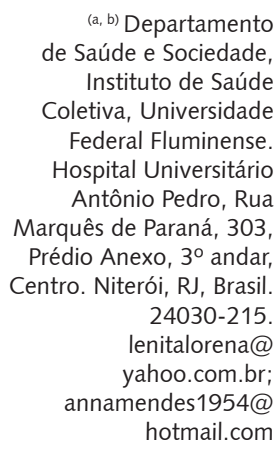

(a, b) Departamento de Saúde e Sociedade, Instituto de Saúde Coletiva, Universidade Federal Fluminense. Hospital Universitário Antônio Pedro, Rua Marquês de Paraná, 303, Prédio Anexo, $3^{\circ}$ andar, Centro. Niterói, RJ, Brasil. 24030-215. lenitalorena@ yahoo.com.br; annamendes1954@ hotmail.com 
Trata-se de uma disciplina que, desde 2012, utiliza a abordagem com estudantes do quinto período do curso.

\section{Uma experiência didática}

Entre as disciplinas obrigatórias do currículo médico está Saúde e Sociedade IV, ministrada pelo Departamento de Saúde e Sociedade. Cerca de oitenta estudantes do quinto semestre são introduzidos à Semiologia Médica e iniciam uma fase do curso em que as aulas, teóricas e práticas, concentram-se no hospital universitário, propiciando um contato próximo com os pacientes atendidos no hospital. A proposta de apresentar-Ihes a abordagem narrativa, nesse momento, tem a finalidade de alargar seus horizontes e recursos em relação à comunicação com os pacientes e à interpretação de suas falas e expressões, tornando-os capazes de utilizar essa abordagem de forma complementar à anamnese tradicional, com vistas a um cuidado mais ampliado e eficiente.

A disciplina é ministrada, para cada turma de quarenta alunos, em dez encontros com duração de quatro horas, das quais duas são dedicadas à construção de narrativas. Os alunos visitam as enfermarias do hospital, onde, individualmente, entrevistam um paciente, de acordo com um roteiro discutido previamente em sala. Os temas que direcionam as entrevistas são os seguintes: aspectos gerais da história de vida; o processo de adoecimento e suas causas; o itinerário terapêutico e a relação com profissionais de saúde; a experiência da hospitalização; e o impacto da doença na vida pessoal, sua evolução e prognóstico. Os alunos são orientados para que a abordagem da entrevista por temas seja feita de forma flexível, priorizando as preferências e necessidades de expressão dos pacientes.

Após as entrevistas, os alunos retornam à sala de aula, onde registram, em seus cadernos, as narrativas sobre o encontro. São orientados a anotar o relato do paciente, sempre que possível, com as palavras deste e na primeira pessoa e, em seguida, registrar suas interpretações e impressões sobre o entrevistado, além dos sentimentos e efeitos da entrevista sobre eles próprios.

Em seguida, solicita-se aos alunos que compartilhem a experiência daquele dia, o que resulta em debates entre eles e as professoras. Nesses momentos, as dificuldades e desafios mais impactantes ou frequentes são debatidos, assim como as possíveis formas de se lidar com estes, o que resulta em estreitamento dos vínculos de solidariedade entre os estudantes.

Com a finalidade de compreender melhor essa experiência, foram analisados os temas que se destacaram, por sua presença mais frequente, nas narrativas produzidas pelos estudantes durante esses quatro anos (2012-2015).

\section{Resultados e discussão}

Os temas que se destacaram são apresentados e discutidos nos itens a seguir.

\section{Admiração pelos pacientes por sua postura diante da doença e generosidade}

Diversos relatos de estudantes demonstram que a conversa com os pacientes redundou em admiração e aprendizado para suas vidas, com exemplos de serenidade, coragem e fé diante das dificuldades trazidas pelo adoecimento e hospitalização e postura positiva diante da vida. Destacamos, como exemplos, algumas narrativas:

Eu me senti muito emocionada com a história do senhor R. Sua vontade de viver, o brilho no olhar e a alegria, mesmo internado, são contagiantes. O modo como fala de sua família e de seu trabalho nos inspiram a fazer o que realmente amamos e a forma como ele utilizou a perda do seu pai para se tornar alguém melhor é uma lição de como lidar com as dificuldades que aparecem na nossa vida. 
A generosidade de vários pacientes em relação aos estudantes, compreensão de suas necessidades de aprendizado e solidariedade com suas demandas também despertaram sentimentos de admiração e respeito:

Ela apresentava quadro de metástases de um câncer em fase terminal e sabia que não lhe restava muito tempo de vida. No entanto se mostrou disposta a nos ajudar, dizendo que poderíamos ficar ali à vontade, o tempo que fosse necessário, pois ficava muito feliz em ajudar no nosso aprendizado. A atitude dessa mulher me fez refletir sobre toda a situação que ela estava passando, como sabia lidar com a doença e utilizar isso para nos ajudar a aprender.

Outros autores encontraram, nas narrativas de estudantes, sentimentos semelhantes de admiração e aprendizado com os exemplos de coragem, altruísmo e capacidade de doação dos pacientes, que fazia aumentar nos estudantes o sentido de responsabilidade e vontade de colaborar com eles ${ }^{17}$.

\section{Insegurança e inibição para abordar os pacientes e temor de incomodá-los}

Outro desafio muito frequente foi a inibição para abordar os pacientes, em função do receio de trazer mais incômodo àqueles que já sofrem com a doença e a hospitalização:

Ainda estou sentindo insegurança para abordar os pacientes, passei por três andares até chegar ao sétimo, onde realizei a entrevista. Havia muitos pacientes dormindo ou com acompanhantes. Finalmente, ao passar pela enfermaria feminina, procurando um paciente que me olhasse com aquele olhar receptivo, encontrei T. Ela foi muito simpática e solícita e respondeu de forma sorridente às perguntas. Quem sabe na próxima entrevista consiga abordar um paciente sem o olhar da T.? Será um desafio!

Medeiros e colaboradores, em estudo semelhante, observaram, nos estudantes, sentimentos de culpa e de estarem sendo invasivos por abordarem os pacientes para obtenção de informações, para o exame físico, em suma, para seu aprendizado pessoal, oferecendo nada ou muito pouco em troca ${ }^{3}$.

\section{Desenvolvimento das habilidades de comunicação}

Em nossa experiência, constatamos que a inibição e o temor de estarem incomodando tendiam a diminuir com a prática das entrevistas e a se desenvolver uma maior facilidade para a abordagem e comunicação com os pacientes:

Foi a melhor experiência que tive desde o início do curso. Saí da enfermaria me sentindo sem um peso nas costas que me incomodava: medo de não conseguir lidar bem com o paciente. Sinto que consigo conversar com qualquer paciente, independente da sua história. Isso eu não aprenderia em livro algum.

Meu primeiro espanto foi que ele fez questão que conversássemos e aquela mesma pessoa com um semblante de tristeza se mostrou feliz e animada em poder conversar. Fiquei em um misto de surpresa e felicidade pelo ocorrido. Após o assunto sobre a doença do paciente, a conversa se deu tão fluida, tão saudável e gostosa de se ter... foi um dos melhores contatos com pacientes que eu já tive. Aprendi muito e, em tão pouco tempo, criei uma ligação forte que eu nem mesmo achava possível ser construída dessa forma.

Uma das queixas mais presentes no discurso dos pacientes era não compreender seu problema de saúde, a linguagem dos profissionais e o que estava sendo programado para a condução de seus casos, 
o que gerava ansiedade, insegurança e angústia. Nesse aspecto, os estudantes perceberam que podem contribuir muito para o bem-estar dos pacientes, ao explicar-lhes com linguagem simples e acessível o que liam nos prontuários:

Ficou claro para mim que o senhor F. não entendia, de fato, o que estava acontecendo em seu organismo. Senti que podia ajudá-lo. Utilizando palavras de fácil compreensão, expliquei para ele sobre seu coração descompensado, sobre o esforço físico, a hipertensão, a diabetes, sobre os rins e a diálise. Percebi que ele ficou satisfeito. Isso me deixou feliz, me senti útil. Fui embora com a sensação do dever cumprido.

A continuidade do exercício das entrevistas levou, para a maior parte dos estudantes, ao desenvolvimento de uma postura mais aberta, solidária e realmente interessada no outro, o que facilitou com que os pacientes se sentissem à vontade para conversar e uma confiança mútua pudesse surgir:

Notei que nossa maior aproximação aconteceu quando comecei a contar minhas experiências e mostrar meu interior. Às vezes queremos que o outro se abra para a gente, mas colocamos uma barreira em frente ao nosso coração. A confiança depende de nos abrirmos para o outro. $\mathrm{O}$ senhor A. C. ficou mais feliz depois de termos conversado. Às vezes só precisamos ouvir e sorrir. A alma também adoece.

Hoje, por ser o último dia das entrevistas, tive a certeza de que, mesmo quando elas acabarem, vou continuar indo nas enfermarias para conversar com os pacientes e não somente para buscar doenças. Hoje fui conversar com a paciente L., que estava internada há mais de um mês. Quando demonstrei que não queria saber da doença e sim dela, ela se surpreendeu e disse: "Ah, mas que beleza, eu gosto tanto de falar, mas os alunos e professores só querem saber de apertar a gente".

Com o desenvolvimento dessa postura e forma de aproximação, os estudantes constatavam que os pacientes, como qualquer pessoa que passa por uma situação difícil, sentiam-se aliviados e satisfeitos por terem a oportunidade de dividir seus problemas com um ouvinte atento e interessado:

Então E. se abriu e deixou sua subjetividade fluir, contou-me sobre seu medo da cirurgia, seu choro e angústia com a notícia, suas crises de hipertensão causadas pela ansiedade précirúrgica, que levaram a que a cirurgia fosse desmarcada várias vezes. Sendo assim, me senti próximo dele e tentei o acolher naquele momento. Foram minutos importantes que certamente me ajudarão no futuro a ser um profissional mais humano. Muitas vezes ouvir é tão importante quanto medicar.

O desenvolvimento de relações empáticas entre profissionais e pacientes é um dos resultados almejados das propostas de humanização da formação e aspecto central das abordagens de medicina centradas no paciente. A empatia pode ser definida como a capacidade de compreender e ser sensível aos sentimentos, ideias e experiências do outro, envolvendo aspectos cognitivos e afetivos. Promover a aquisição desta qualidade envolve a transformação de perspectivas, a autorreflexão e a internalização de valores humanísticos ${ }^{6}$. Vale lembrar também que a empatia e a habilidade comunicacional interferem nos resultados da ação médica, pois aumentam a satisfação, a confiança e a adesão dos pacientes $^{3}$.

\section{Dificuldade em lidar com o sofrimento e com a expressão de emoções}

O contato com pacientes que estavam sofrendo e a sensação de impotência para ajudá-los foi, em muitos momentos, um desafio para os estudantes. Outro desafio foi lidar com a expressão de emoções 
de tristeza, desalento e desesperança da parte dos pacientes entrevistados. A dificuldade em escolher ficar em silêncio ou falar alguma coisa e em escolher as palavras para serem ditas nesses momentos trouxe à tona aspectos da formação médica que são muito pouco abordados.

Dentre as várias perguntas, a que mais me deixou sem ação foi quando ele chorou ao falar que o médico havia dito que ele não andaria mais. Fiquei desconfortável com a situação e tentei mudar o foco da conversa. Depois descobri que, às vezes, é bom deixar o paciente expressar suas emoções naquele momento e esperar.

Como alguns autores ressaltam, a comunicação empática entre estudante/profissional e paciente está embasada na habilidade de ajudá-lo a construir sua narrativa, com interesse genuíno em compreendê-lo ${ }^{13}$. Um aprendizado necessário na formação de um médico é identificar os sentimentos dos pacientes e responder efetivamente às suas manifestações emotivas, sem reprimi-las ou julgálas, mas buscando ajudá-los a lidar com elas. Emoções de natureza diversa estão frequentemente envolvidas em situações difíceis como o adoecimento e seus desdobramentos. Reconhecer que essas emoções fazem parte do processo e têm um impacto importante na saúde e no bem-estar é o primeiro passo para se tentar lidar com elas da melhor forma possível $9^{9,18}$.

Porém, aprender a identificar e lidar com as emoções do outro passa, primeiramente, por reconhecer e lidar com suas próprias emoções e sentimentos, habilidade que, com frequência, é ignorada na formação médica ${ }^{18}$. Ainda é frequente que estudantes relatem que têm aprendido, por meio do chamado currículo oculto, que as emoções devem ser abafadas e negadas no relacionamento com os pacientes e seus familiares, pois podem prejudicar o discernimento e a autoridade necessários para a prática médica ${ }^{9,19}$.

O distanciamento emocional e afetivo entre médicos e pacientes é a consequência mais direta desse posicionamento, trazendo dificuldades para essa relação e para o próprio equilíbrio emocional dos estudantes e profissionais. Negar as emoções não significa, de modo algum, superá-las; embora camufladas, elas continuarão atuando no campo psíquico, podendo gerar desconforto, ansiedade, insegurança e outras consequências mais graves, como estresse e depressão, infelizmente comuns entre médicos e estudantes de medicina ${ }^{3,18}$.

O exercício de buscar identificar seus próprios sentimentos no momento da conversa com o paciente e registrá-lo, como parte da narrativa a ser construída, na nossa experiência, tinha a finalidade de ajudar os estudantes a se tornarem mais conscientes de seu próprio campo emocional e compreenderem a relevância disso. Grande parte mostrou dificuldade inicial em identificar e narrar seus próprios sentimentos e poucos se encorajavam a compartilhá-los, no fim do processo, com a turma, mas essa dificuldade tendeu a diminuir com o exercício e o incentivo das professoras.

Quando iniciei a entrevista, eu não estava me sentindo muito bem. Tenho me sentido muito ansiosa com as provas e também com outras mudanças que têm ocorrido em minha vida. Falar com A. C. foi um momento muito agradável para mim. Tentar me colocar em seu lugar foi difícil, pois nem imagino se conseguiria passar por uma situação assim. Fez-me pensar sobre a minha própria vida, meus valores e prioridades.

Segundo alguns autores, a capacidade de reflexão pode ser aprendida e desenvolvida por meio do exercício, especialmente o exercício de escrever a respeito de experiências, ideias e sentimentos. Posteriormente, compartilha-se e discute-se com outros sobre o que foi escrito e suas interpretações, consistindo na chamada escrita reflexiva ${ }^{7,20}$. A reflexão influencia o desenvolvimento da empatia e é por esta influenciada. Médicos e estudantes que refletem sobre seus próprios sentimentos e suas vidas tornam-se mais disponíveis e capazes de ajudar os pacientes ${ }^{13}$.

Outro grande desafio, que encontramos expresso nas narrativas dos estudantes, foi ouvir ou ser solicitado a conversar a respeito de diagnósticos difíceis, com mau prognóstico. Essa dificuldade foi apontada igualmente em outros estudos ${ }^{14,17}$. 
Eu fiquei ouvindo, esperando ele falar mais alguma coisa. Aí, meio sem saber o que fazer ainda, falei para ele se acalmar, que era necessário fazer essa biópsia e que os médicos queriam fazer o melhor para ele. Quase chorei junto com ele. Imaginei como seria se eu estivesse no seu lugar, sem entender muito bem o que estava acontecendo comigo. Após a nossa conversa, consegui acalmá-lo e ele me agradeceu e pediu que eu voltasse mais vezes lá.

\section{Compreensão dos problemas, experiências e pontos de vista dos pacientes}

A relação de confiança estabelecida com os alunos permitia que muitos pacientes compartilhassem com eles suas histórias de vida difíceis e problemas sociais graves, que se somavam aos problemas de saúde, desencadeando reações de preocupação e solidariedade da parte dos estudantes:

Foi uma entrevista difícil, pois a vida da paciente foi marcada por muito sofrimento. Seus relatos sobre o estado da casa em que mora são horríveis e sua família está em situação de vulnerabilidade social. A maioria dos filhos e dos netos está ligada às drogas e ao crime, sem nunca terem recebido qualquer tipo de apoio para sair dessas condições. É muito difícil ouvir um paciente falar sobre essas dificuldades e se sentir impotente. Enquanto ela falava sobre suas inúmeras necessidades de saúde, eu ia pensando nas falhas do sistema e no que poderia ter sido feito anteriormente para aliviar o sofrimento desta senhora.

Compreender a experiência da hospitalização por meio do olhar dos pacientes que a vivenciam foi outra importante contribuição que as entrevistas trouxeram para os estudantes. A dificuldade em estar em um ambiente estranho, algumas vezes hostil, longe dos familiares; e, por outro lado, o apoio mútuo que os pacientes das enfermarias se proporcionam, estavam muito presentes nas narrativas, assim como o apoio aos pacientes por profissionais e estudantes, o que trouxe aos alunos a confirmação de que podem ser úteis, mesmo nessa fase precoce da sua formação.

Outros autores mostraram que o retorno positivo e gratidão dos pacientes em relação aos tipos de ajuda que os estudantes são capazes de prestar, mesmo em uma fase inicial do curso, como ouvi-los com atenção e fornecer-lhes explicações em linguagem acessível, encorajam e tornam os estudantes mais confiantes e confortáveis no ambiente hospitalar ${ }^{17}$.

Outra lição fundamental foi ouvir, no relato dos pacientes, o que representa para eles um bom médico, um bom profissional de saúde. Ser atencioso e aliar o conhecimento técnico à capacidade de comunicar-se, compreender aquele que está doente além dos aspectos orgânicos da doença, eram qualidades de um "bom médico" que reforçaram, para os estudantes, aprendizados que eles já tiveram sobre atenção integral e humanização:

Assim, o senhor C. afirmou que "um bom médico é aquele que é atencioso e que tem, além do conhecimento técnico, a preocupação com a nossa vida fora da doença", isto é, o médico, para ter um bom atendimento e ser um bom médico, deve olhar o paciente em todos os seus aspectos - biológico, familiar e social.

O senhor J. me elogiou pela atenção e cuidado ao iniciar e durante a nossa conversa. Isso me deixou muito satisfeito. Ganhei meu dia ali! Sobre o que considerava ser um bom médico, disse que é aquele que ouve, dá atenção, se preocupa com o paciente, não só com a sua doença. Ao ouvir essas palavras, me lembrei de toda a abordagem teórica sobre cuidado integral e abrangência biopsicossocial. O senhor J. me fez entender a importância de toda aquela teoria. Ali estava um paciente me dando aula prática sobre saúde e sociedade.

Um aspecto relevante da educação médica é a construção da identidade profissional. A identidade social, um aspecto fundamental da vida em sociedade, é caracterizada essencialmente pela forma como 
nós próprios nos vemos, conjugada com a forma como os outros nos veem. Os médicos em formação gradualmente vão desenvolvendo seu pertencimento a essa classe profissional e sua identidade profissional. A abordagem narrativa propicia situações pedagógicas nas quais o estudante tem a oportunidade de refletir, junto com colegas, sobre sua identidade profissional emergente e sobre sua identidade pessoal, o que gera autoconhecimento e amadurecimento ${ }^{3,14}$.

Enquanto entrevistava R., sentia que estava evoluindo, como acadêmico e como gente, ser humano. Estava mais atento. Mais experiente. Coisas que ela me falou me marcarão para sempre. Com certeza. O médico como um profissional distante, intocável, ainda existe e é como muitos pacientes enxergam. As considerações dela com certeza me ajudaram a incutir em mim a vontade de não ser assim, frio, técnico, mecânico demais. São coisas que a gente vai aprendendo ao ouvir os pacientes.

\section{Estabelecimento de vínculos com os pacientes}

A oportunidade de aproximar-se dos pacientes, ouvi-los com atenção e demonstrar sincero interesse por eles e por seus problemas resultou no estabelecimento de vínculos afetivos e relações de amizade e cumplicidade entre estudantes e pacientes, que foram enriquecedoras para ambos, contribuindo para minimizar as dificuldades, de um lado, do adoecimento e hospitalização e, do outro, das pressões exercidas pelo curso médico:

Foi uma conversa interessante e descontraída, conversamos sobre futebol, Copa do Mundo, seleção brasileira. Consegui arrancar alguns sorrisos de M. T. W., o que me deixou muito feliz. Creio que em vinte minutos de conversa pude fazê-lo esquecer, pelo menos um pouco, sua doença. Tive uma impressão muito boa sobre a conversa. Eu nunca tinha tido uma relação assim com um paciente. Parecia que não estávamos num hospital, mas sim num bar, como bons amigos. Pretendo levar essa boa relação para os próximos pacientes.

Fiquei comovida pelo sofrimento que ele parece estar passando. Queria poder fazer algo para ajudá-lo, mas no momento o que eu podia fazer era conversar com ele. E ao nos despedirmos, falei que torcia muito pela sua recuperação e que iria rezar pela sua saúde. Pela primeira vez, durante nossa conversa, ele levantou a cabeça e olhou nos meus olhos. Até então, ele estava com a cabeça baixa e eu fiquei com medo de estar atrapalhando. Nessa hora percebi o quanto ele gostou daquela breve conversa, pela maneira com que ele olhou nos meus olhos. Muitas vezes o que a pessoa mais precisa é ouvir alguém ou ter alguém que possa escutá-la. Realmente o contato humano é insubstituível. Voltei na semana seguinte para saber como S. R. estava. Comecei perguntando se ele lembrava de mim, ele disse: “Lógico que lembro, estava triste semana passada e você veio bater um papo comigo, como iria esquecer? Achei sensacional, cada vez mais percebo que posso estar ajudando ao invés de atrapalhando quando vou abordar os pacientes na enfermaria."

A fase em que o estudante passa para o chamado "ciclo profissional" ou a etapa do curso médico em que as aulas se dão no ambiente hospitalar e são voltadas para a clínica, representa um verdadeiro rito de passagem, como alguns autores têm apontado. Nesse momento, surgem, com frequência, conflitos emocionais, angústias, insegurança e dificuldades de adaptação ao novo contexto, em que as narrativas podem representar um espaço de expressão e elaboração desses conflitos, com importante valor pedagógico 3,8 .

Estudos publicados sobre experiências semelhantes têm mostrado que estar com pacientes, conversar com eles e ouvir suas histórias ajudam os estudantes a manter-se em equilíbrio frente às exigências curriculares e é, para eles, fonte de aprendizado tão valiosa quanto os livros acadêmicos ${ }^{17}$. 


\section{Conclusões}

Observamos uma grande adesão dos estudantes à proposta da disciplina e um investimento crescente na construção das narrativas. A experiência de conversar com os pacientes de uma forma mais aberta e disponível trouxe, para eles, lições importantes para sua formação médica e para suas vidas. Compreender o processo de adoecimento, a trajetória em busca de ajuda, as consequências que a doença trouxe para suas vidas, a experiência da hospitalização e o que os pacientes consideram um bom médico são resultados dessa experiência pedagógica que, sem dúvida, tiveram grande impacto no perfil e na postura desses médicos em formação.

Desafios e dificuldades, que também fizeram parte da experiência, foram igualmente fontes de aprendizados valiosos: a inibição inicial em abordar os pacientes e o receio de incomodá-los; o contato com o sofrimento e a sensação de impotência diante dele; a reação diante da expressão de sentimentos de tristeza por parte dos pacientes; e a consciência e expressão de seus próprios sentimentos.

$\mathrm{Na}$ fase do curso em que se inicia o contato direto com pacientes hospitalizados e em que as aulas e atividades passam a ocorrer, predominantemente, no ambiente hospitalar, a utilização das narrativas representou um espaço de expressão e ajuda para que os estudantes pudessem melhor compreender e elaborar os conflitos, angústias e inseguranças vinculados a esse "rito de passagem" no processo de construção de suas identidades e perfis profissionais. Os estudantes foram também encorajados a incorporar, na anamnese tradicional à qual estavam também sendo introduzidos, as habilidades desenvolvidas com a experiência narrativa.

Destacamos, assim, a relevância da abordagem narrativa como facilitadora do autoconhecimento; da reflexão; do desenvolvimento de habilidades empáticas e de comunicação; e da capacidade de identificar, compreender e lidar com as emoções do outro e com suas próprias emoções e recomendamos sua utilização como ferramenta de ensino-aprendizagem na formação médica.

\section{Colaboradores}

As autoras participaram de todas as etapas de elaboração do artigo, da discussão dos resultados e da revisão e aprovação da versão final do trabalho.

\section{Referências}

1. Benedetto MAC. Entre dois continentes: literatura e narrativas humanizando médicos e pacientes. Mundo Saude. 2010; 34(3):311-9.

2. Grossman $\mathrm{E}$, Cardoso MHCA. As narrativas em medicina: contribuições à prática clínica e ao ensino médico. Rev Bras Educ Med. 2006; 30(1):6-14.

3. Medeiros NS, Santos TR, Trindade EMV, Almeida KJQ. Avaliação do desenvolvimento de competências afetivas e empáticas do futuro médico. Rev Bras Educ Med. 2013; 37(4):515-25.

4. Favoreto $\mathrm{CAO}$, Camargo Jr KR. A narrativa como ferramenta para o desenvolvimento da prática clínica. Interface (Botucatu). 2011; 15(37):473-83.

5. Charon R. Narrative medicine: a model for empathy, reflection, profession, and trust. JAMA. 2001; 286(15):1897-902. 
6. Kumagai A. A conceptual framework for the use of illness narratives in medical education. Acad Med. 2008; 83(7):653-8.

7. Charon R. Narrative medicine: form, function, and ethics. Ann Intern Med. 2001; 134(2):83-7.

8. Benedetto MAC, Garcia D, Blasco PG. Era uma vez... narrativas em medicina. Rev Bras Cuid Paliat. 2010; 3(1):19-25.

9. Leeuw S, Parkes MW, Thien D. Questioning medicine's discipline: the arts of emotions in undergraduate medical education. Emot Space Soc. 2014; 11:43-51.

10. Greenhalgh T, Hurwitz B. Narrative based medicine: why study narrative? Br Med J. 1999; 318(2):48-50.

11. Gaver A, Borkan JM, Weingarten MA. Illness in context and families as teachers: a year-long project for medical students. Acad Med. 2005; 80(5):448-51.

12. Miller E, Balmer D, Hermann N, Graham G, Charon R. Sounding narrative medicine: studying students' professional identity development at Columbia University College of Physicians and Surgeons. Acad Med. 2014; 89(2):335-42.

13. DasGupta $S$, Charon R. Personal illness narratives: using reflective writing to teach empathy. Acad Med. 2004; 79(4):351-6.

14. Clandinin J, Cave MT, Cave A. Narrative reflective practice in medical education for residents: composing shifting identities. Adv Med Educ Pract. 2011; 2:1-7.

15. Wald HS, Borkan JM, Taylor JS, Anthony D, Reis SP. Fostering and evaluating reflective capacity in medical education: developing the REFLECT rubric for assessing reflective writing. Acad Med. 2012; 87(1):41-50.

16. Arjmand S. The use of narrative in medical education. J Learn Arts. 2012; 8(1):1-8.

17. Dyrbye LN, Harris I, Rohren $\mathrm{CH}$. Early clinical experiences from students' perspectives: a qualitative study of narratives. Acad Med. 2007; 82(10):979-88.

18. Shapiro J. Does medical education promote professional alexithymia? A call for attending to the emotions of patients and self in medical training. Acad Med. 2011; 86(3):326-32.

19. Gaufberg EH, Batalden M, Sands R, Bel SK. The hidden curriculum: what can we learn from third-year medical student narrative reflections? Acad Med. 2010; 85(11):1709-16.

20. Charon R, Hermann N. A sense of story, or why teach reflective writing? Acad Med. 2012; 87(1):5-7. 
Descreve-se uma experiência didática de utilização da abordagem narrativa com estudantes do terceiro ano do curso médico da Universidade Federal Fluminense. A análise de suas narrativas revelou temas como admiração pelos pacientes por sua coragem e generosidade; inibição inicial de abordá-los e receio de incomodá-los; facilidade progressiva para a comunicação; dificuldades em lidar com seu sofrimento e com a expressão de suas emoções; compreensão de seus problemas, pontos de vista e experiências; e estabelecimento de relações de amizade e cumplicidade com os pacientes. A proposta pedagógica mostrou-se capaz de ampliar a compreensão dos estudantes sobre o processo de adoecimento e a experiência da hospitalização, aprofundar o vínculo estudante-paciente, facilitar o autoconhecimento, reflexão, desenvolvimento de habilidades empáticas e de comunicação e da capacidade de identificar e compreender e lidar com as emoções do outro e com suas próprias emoções.

Palavras-chave: Educação médica. Medicina narrativa. Empatia.

\section{An experience of using narratives in medical students' education}

In this paper, we describe a teaching experience of using the narrative approach with students in their third year of medical school at the Universidade Federal Fluminense. The analysis of their narratives pointed to themes that included admiration for their patients' courage and generosity; an initial reticence to approach them, and a fear of disturbing them; a growing capability in communication; difficulties in dealing with their suffering and with expressing their emotions; understanding of their problems, points of view and experiences; and the establishment of relationships with patients based on friendliness and solidarity. The pedagogical approach of using narratives proved useful in terms of expanding the students' understanding of the illness process and the experience of hospitalization, improving the student-patient relationship, facilitating self-awareness, reflection, the development of skills relating to empathy and communication, and the ability to identify, understand and deal with the emotions of others and with their own emotions.

Keywords: Medical education. Narrative medicine. Empathy.

\section{Una experiencia del uso de narrativas en la formación de estudiantes de medicina.}

Se describe una experiencia didáctica de utilización del abordaje narrativo con estudiantes del tercer año del curso médico de la Universidad Federal Fluminense. El análisis de sus narrativas reveló temas como admiración por los pacientes por su coraje y generosidad, inhibición inicial de abordarlos y recelo de molestarlos, facilidad progresiva para la comunicación, dificultades para enfrentar su sufrimiento y con la expresión de sus emociones, comprensión de sus problemas, puntos de vista y experiencias y establecimiento de relaciones de amistad y complicidad con los pacientes. La propuesta pedagógica se mostró capaz de ampliar la comprensión de los estudiantes sobre el proceso de enfermarse y la experiencia de la hospitalización, profundizar el vínculo estudiantepaciente, facilitar el auto-conocimiento, la reflexión, el desarrollo de habilidades empáticas y de comunicación y de la capacidad de identificar, comprender y enfrentar las emociones del otro con sus propias emociones.

Palabras clave: Educación. Medicina narrativa. Empatía. 